\title{
CARACTERIZAÇÃO FÍSICA DA ÁREA DE PROTEÇÃO AMBIENTAL DE JENIPABU (APAJ)
}

\author{
Physical characterization of the Jenipabu environmental protection area (APAJ) \\ Caracterización física del área de protección ambiental de Jenipabu (APAJ)
}

\author{
Ivaniza Sales Batista1 \\ Zuleide Maria Carvalho Lima² \\ Juliana Felipe Farias ${ }^{3}$ \\ Nadeline Hevelyn de Lima Araujo 4 \\ Erick Jordan da Silva Gomes 5
}

\begin{abstract}
RESUMO
Área da Proteção Ambiental de Jenipabu (APAJ), localizada no Rio Grande do Norte (RN), trata-se de uma Unidade de Conservação (UC) enquadrada na categoria de uso sustentável, de modo a permitir 0 uso direto dos seus recursos e potencialidades. Este fator, corrobora no aumento da probabilidade de degradação dos seus ecossistemas, a depender das formas de ocupação do solo. Este artigo se objetiva caracterizar os aspectos físico-naturais da APAJ. A metodologia adotada baseou-se em pesquisas bibliográfica e de campo, assim como, produções cartográficas. Enquanto resultados, a APAJ é caracterizada pela diversidade dos seus aspectos físico-naturais, sobressaindo ecossistemas de praias, dunas, manguezal e tabuleiros. Portanto, salienta-se a importância desempenhada por uma gestão participativa (composta por gestores e comunidades locais), visando o equacionamento de conflitos e a proteção/conservação dos ecossistemas e biodiversidade local.
\end{abstract}

Palavras chaves: Unidades de Conservação (UC's); Área da Proteção Ambiental de Jenipabu (APAJ); Caracterização física.

\footnotetext{
${ }^{1}$ Mestre, licencianda e Bacharela em Geografia pela Universidade Federal do Rio Grande do Norte, e-mail: ivanizas@ymail.com

2Profa. Pós-Dra ${ }^{2}$ do Departamento de Geografia da Universidade Federal do Rio Grande do Norte, e-mail: zmclima@hotmail.com

${ }^{3}$ Profa. Pós-Dra . do Departamento de Geografia da Universidade Federal do Rio Grande do Norte, e-mail: julianafelipefarias@yahoo.com.br

¿Licencianda e Bacharela em Geografia pela Universidade Federal do Rio Grande do Norte, e-mail: nadelinehevellyn@hotmail.com

${ }^{5}$ Mestrando licenciando e Bacharel em Geografia pela Universidade Federal do Rio Grande do Norte, e-mail: erickjordangeo@gmail.com
} 


\begin{abstract}
Jenipabu Environmental Protection Area (APAJ), located in Rio Grande do Norte (RN), it is a Conservation Unit (UC) framed in the category of sustainable use, in order to allow the direct use of its resources and potentialities. This factor, corroborates in the increase in the probability of degradation of their ecosystems, depending on the forms of soil occupation. This article aims to characterize the physical-natural aspects of the APAJ. The methodology adopted was based on bibliographical and field research, as well as cartographic productions. As a result, the APAJ is characterized by the diversity of its physical and natural aspects, highlighting ecosystems of beaches, dunes, mangroves and trays. Therefore, the importance of participatory management (composed of local managers and communities), aiming at the equation of conflicts and the protection / conservation of ecosystems and local biodiversity.

Keywords: Conservation Units (UC's) Jenipabu Environmental Protection Area (APAJ); Physical characterization.

\section{RESUMEN}

El Área de Protección Ambiental de Jenipabu (APAJ), ubicada en Rio Grande do Norte (RN), es una Unidad de Conservación (UC) clasificada en la categoría de uso sostenible, para permitir el uso directo de sus recursos y

potencialidades. Este factor corrobora la mayor probabilidad de degradación de sus ecosistemas, dependiendo de las formas de ocupación de la tierra. Este artículo tiene como objetivo caracterizar los aspectos físico-naturales de APAJ. La metodología adoptada se basó en la investigación bibliográfica y de campo, así como en producciones cartográficas. Como resultado, APAJ se caracteriza por la diversidad de sus aspectos físicos y naturales, destacando los ecosistemas de playas, dunas, manglares y bandejas. Por lo tanto, se enfatiza la importancia del manejo participativo (compuesto por administradores y comunidades locales), con el objetivo de la resolución de conflictos y la protección I conservación de los ecosistemas y la biodiversidad local.

Palabras clave: Unidades de Conservación (UC); Área de Protección Ambiental de Jenipabu (APAJ); Caracterización física
\end{abstract}

\title{
INTRODUÇÃO
}

A Área de Proteção Ambiental de Jenipabu (APAJ), localiza-se entre os municípios de Extremoz e Natal (MAPA 1), integrando um conjunto composto por dezoito Unidades de Conservação (UC's) no estado do Rio Grande do Norte (RN). Nas palavras de Medeiros (2004), elas compreendem áreas protegidas (cuja delimitação e definição deram-se de forma previa) que permitem a intervenção com uso e fins específicos, com o intuito de protegê-las, através de um ato do Poder Público (lei, decreto, etc).

Inserida no grupo de UC's de uso sustentável, a APAJ admite o uso direto dos seus recursos e potencialidades, o que contribui para o aumento da probabilidade de degradação dos seus ecossistemas, a depender das práticas socioespaciais realizadas, localmente. A área em estudo apresenta aspectos físico-naturais diversos, bastante dinâmicos e complexos, sobressaindo na paisagem a espacialização de feições associadas praias, dunas, lagoas interdunares e tabuleiros, as quais vêm sendo exploradas, sobretudo, por atividades turísticas (BATISTA, 2018).

Sua criação apresentou como objetivo a promoção do ordenamento do uso e proteção dos ecossistemas locais e sua biodiversidade, tendo em vista que os mesmos são ameaçados pelas atividades existentes, assim como, o uso e ocupação do solo. Outro fator determinante, foi seu 
posicionamento geográfico estratégico, ao formar um corredor ecológico com as Zonas de Proteção Ambiental (ZPA's) 8 e 9 do Plano Diretor de Natal, de modo a favorecer o fluxo gênico e a dispersão de espécies (BATISTA, 2018).

Mapa 1 - Localização da Área de Proteção Ambiental de Jenipabu - APAJ (área em estudo)

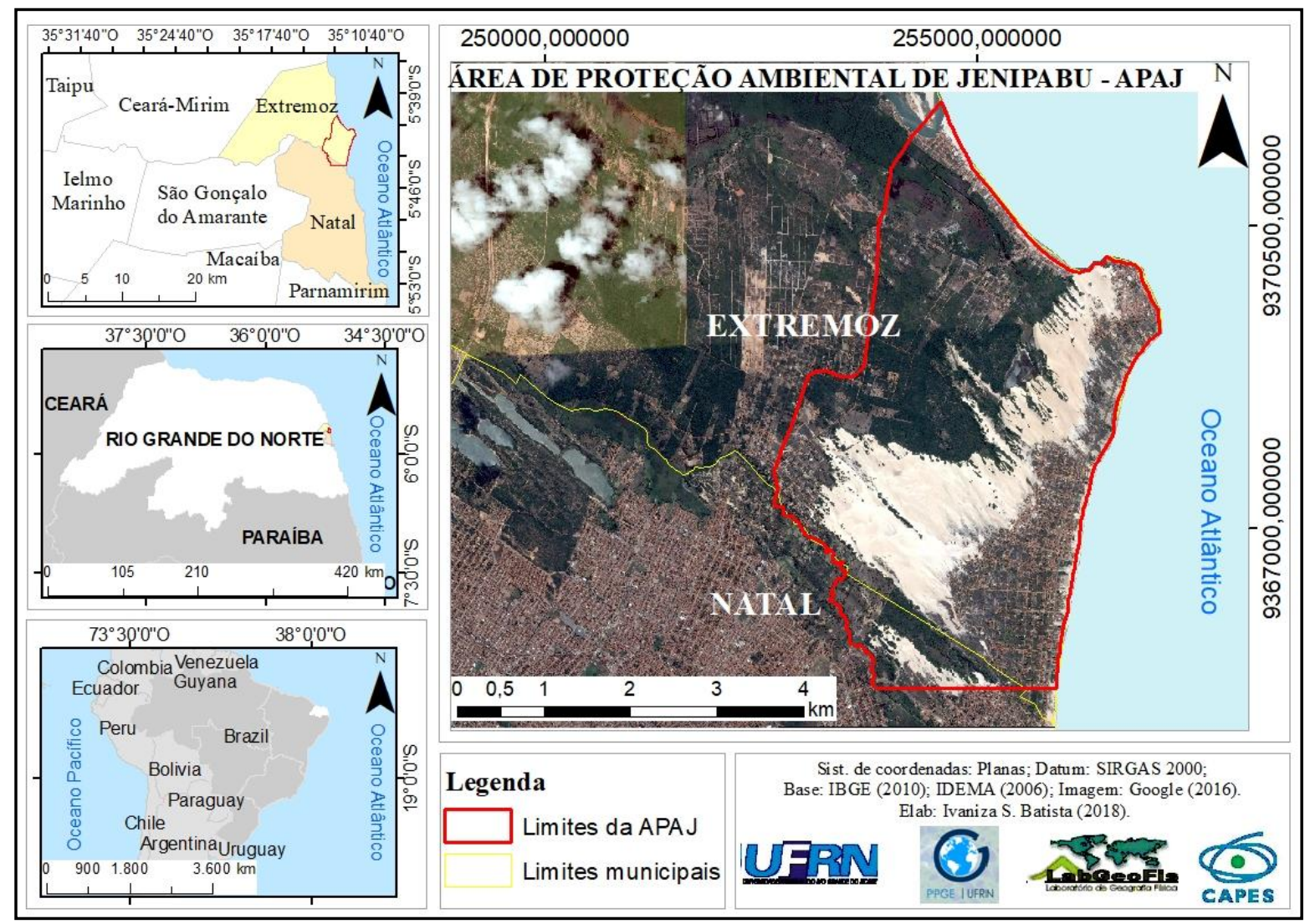

FONTE: Batista (2018).

Este artigo teve como objetivo caracterizar os aspectos físico-naturais da APAJ, buscando elucidar a dinamicidade e interação entre os sistemas geoambientais locais, alertando sobre a importância desempenhada por uma gestão participativa (composta por gestores e comunidades locais), visando o equacionamento de conflitos e a proteção/conservação dos ecossistemas e biodiversidade local. Para tanto, pautamo-nos em pesquisas bibliográficas e de campo, produções cartográficas.

\section{MATERIAIS E MÉTODOS}

Foi realizada a aquisição de informações por intermédio das pesquisas bibliográfica e de campo. Nos trabalhos de campo, foram efetivadas observações técnicas e registros fotográficos na área em estudo, para tanto, fez-se necessário à utilização instrumentos de apoio, tais como, câmera fotográfica, caderneta de campo e um Global Positioning System (GPS - Sistema de Posicionamento Global), modelo 
79 CSX, marca Garmim). Para a elaboração dos mapas temáticos, foram utilizadas informações de bancos de dados existentes (shapefiles), manipuladas na plataforma Arc Gis 10.3, versão trial para estudantes (ESRI).

\section{RESULTADOS E DISCUSSÕES}

A criação de áreas legalmente protegidas constituí-se em uma importante estratégia para a preservação e/ou conservação de ecossistemas e biodiversidade de uma determinada área. Tendo em vista que relações e práticas sociais contribuem para o desencadeamento de alterações significativas e diversas ao meio, de modo a comprometê-lo (BATISTA, 2018). A APAJ apresenta um mosaico de ecossistemas de campos de praias, dunas, lagoas e tabuleiros, caracterizados pela grande dinamicidade dos sistemas geoambientais locais, evidenciada pela remodelagem rápida de suas formas.

\section{Unidades de Conservação (UC's)}

Os Estados Unidos, foram pioneiros na criação de áreas legalmente protegidas ao criar o Parque Nacional de Yellowstone, nos anos de 1872, a partir de então, muitos países no mundo seguiram 0 exemplo. No Brasil, este movimento teve sua concretude com a implementação do Parque Nacional de Itatiaia, em 1937 (FARIA E PIRES, 2007), tendo como impulso a determinação da Constituição Federal no art. 225 , inciso $1^{\circ}$, que alertou para a necessidade de

\footnotetext{
definir, em todas as unidades da Federação, espaços territoriais e seus componentes a serem especialmente protegidos, sendo a alteração e a supressão permitidas somente através de lei, vedada qualquer utilização que comprometa a integridade dos atributos que justifiquem sua proteção.
}

Porém, somente em 18 de Julho do ano 2000, através da Lei 9.985, foi instaurada a política nacional de áreas protegidas, através do Sistema Nacional de Unidades de Conservação (SNUC). Contemplando o conjunto de UC's federais, estaduais, municipais e privadas, com a finalidade de efetuar o planejamento e a administração integrada de todas elas, além de apresentar o papel de reforçar a representatividade e a relevância das mesmas no cenário nacional (BATISTA, 2018). Conforme disposto na lei supracitada, em seu art. 20, inciso I, uma UC corresponde a um

espaço territorial e seus recursos ambientais, incluindo as águas jurisdicionais, com características naturais relevantes, legalmente instituído pelo Poder Público, com objetivos do Nordeste brasileiro, p. 904-924, Set. 2019, http://uvanet.br/rcgs. ISSN 2316-8056 @ 1999, Universidade Estadual Vale do Acaraú. Todos os direitos reservados. 
de conservação e limites definidos, sob regime especial de administração, ao qual se aplicam garantias adequadas de proteção (BRASIL, 2000).

Assim, reitera-se a relevâncias das mesmas para a proteção de espaços com significativo valor ambiental (BATISTA, 2018). Ademais, o SNUC teve sua criação com o intuito de fortalecer, planejamento e administração as UC's, visando a garantia da conservação dos recursos naturais e das práticas sociais locais, por meio de um viés de sustentabilidade (BRASIL, 2018b). No que se concerne às definições de formas de uso, têm-se doze categorias de manejo, individualizadas conforme à forma de proteção e usos permitidos (QUADRO 1). Faria e Pires (2007) enfatizam que as áreas protegidas de uso sustentável devem apresentar um manejo que priorize a interpretação ambiental e possibilite a interação da comunidade, assim como, a visitação na UC, com o objetivo de popularizar o conhecimento produzido localmente e fazer com quem todos apreendam sua importância e objetivos de existência.

Quadro 1 - Unidades de Conservação: categorias de manejo

\begin{tabular}{|c|c|c|}
\hline & CATEGORIAS & DESCRIÇÃO \\
\hline & $\begin{array}{c}\text { Área de Proteção } \\
\text { Ambiental }\end{array}$ & $\begin{array}{l}\text { Área em geral extensa, com certo grau de ocupação humana, dotada } \\
\text { de atributos naturais, estéticos e culturais importantes para a qualidade } \\
\text { de vida e o bem-estar das populações. }\end{array}$ \\
\hline $\bar{\Phi}$ & $\begin{array}{l}\text { Área de Relevante } \\
\text { Interesse } \\
\text { Ecológico }\end{array}$ & $\begin{array}{l}\text { Área de pequena extensão, com pouca ou nenhuma ocupação } \\
\text { humana e com características naturais singulares, cujo objetivo é } \\
\text { manter ecossistemas naturais de importância regional ou local e } \\
\text { regular o uso admissível dessas áreas. Permite a existência de } \\
\text { propriedades privadas em seu interior. }\end{array}$ \\
\hline 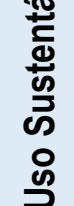 & Floresta & $\begin{array}{l}\text { Área com cobertura florestal onde predominam espécies nativas, cujo } \\
\text { principal objetivo é o uso sustentável e diversificado dos recursos } \\
\text { florestais e a pesquisa científica. }\end{array}$ \\
\hline & $\begin{array}{l}\text { Reserva } \\
\text { Extrativista }\end{array}$ & $\begin{array}{l}\text { Área natural com o objetivo principal de proteger os meios, a vida e a } \\
\text { cultura de populações tradicionais, cuja subsistência baseia-se no } \\
\text { extrativismo e, ao mesmo tempo, assegurar o uso sustentável dos } \\
\text { recursos naturais existentes. }\end{array}$ \\
\hline & Reserva de Fauna & $\begin{array}{l}\text { Área com populações animais de espécies nativas, terrestres ou } \\
\text { aquáticas, onde são incentivados estudos técnico-científicos sobre o } \\
\text { manejo econômico sustentável dos recursos faunísticos. }\end{array}$ \\
\hline
\end{tabular}
do Nordeste brasileiro, p. 904-924, Set. 2019, http://uvanet.br/rcgs. ISSN 2316-8056 ๔ 1999, Universidade Estadual Vale do Acaraú. Todos os direitos reservados. 


\begin{tabular}{|c|c|c|}
\hline & $\begin{array}{l}\text { Reserva de } \\
\text { Desenvolvimento } \\
\text { Sustentável }\end{array}$ & $\begin{array}{l}\text { Área natural onde vivem populações tradicionais que se baseiam em } \\
\text { sistemas sustentáveis de exploração dos recursos naturais. }\end{array}$ \\
\hline & $\begin{array}{l}\text { Reserva Particular } \\
\text { do Patrimônio } \\
\text { Natural }\end{array}$ & $\begin{array}{l}\text { Área privada criada para proteger a biodiversidade a partir de iniciativa } \\
\text { do proprietário. }\end{array}$ \\
\hline \multirow{5}{*}{ 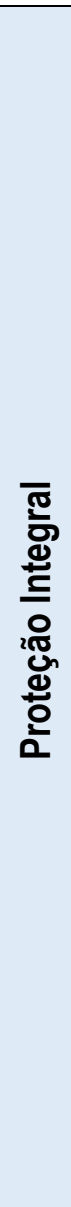 } & Estação Ecológica & $\begin{array}{l}\text { Área destinada à preservação da natureza e à realização de pesquisas } \\
\text { científicas. }\end{array}$ \\
\hline & Reserva Biológica & $\begin{array}{l}\text { Área destinada à preservação da diversidade biológica, onde podem } \\
\text { ser efetuadas medidas de recuperação de ecossistemas alterados e } \\
\text { de preservação e recuperação do equilíbrio natural, da diversidade } \\
\text { biológica e dos processos ecológicos naturais. }\end{array}$ \\
\hline & Parque & $\begin{array}{l}\text { Área destinada à proteção dos ecossistemas naturais de grande } \\
\text { relevância ecológica e beleza cênica, onde podem ser realizadas } \\
\text { atividades de recreação, educação e interpretação ambiental, além de } \\
\text { serem desenvolvidas pesquisas científicas. }\end{array}$ \\
\hline & $\begin{array}{l}\text { Monumento } \\
\text { Natural }\end{array}$ & $\begin{array}{l}\text { Área que tem como objetivo básico a preservação de lugares } \\
\text { singulares, raros e de grande beleza cênica. Permite a existência de } \\
\text { propriedades privadas em seu interior. }\end{array}$ \\
\hline & $\begin{array}{l}\text { Refúgio de Vida } \\
\text { Silvestre }\end{array}$ & $\begin{array}{l}\text { Ambiente natural onde se asseguram condições para a existência ou } \\
\text { reprodução de espécies ou comunidades da flora local e da fauna } \\
\text { residente ou migratória. Permite a existência de propriedades privadas } \\
\text { em seu interior. }\end{array}$ \\
\hline
\end{tabular}

FONTE: BRASIL (2000). Organizado por Batista (2018).

Todavia, na prática, observa-se um grande distanciamento histórico entre as políticas públicas de desenvolvimento econômico e as proteção ambiental, de modo a contribuir para o elevado grau de degradação dos ecossistemas (MEDEIROS, 2007). Em termos quantitativos, no Cadastro Nacional de Unidades de Conservação do MMA (BRASIL, 2018c), o país dispõe do total de 2.144 UC's, enquanto 0 RN apresenta 18 (QUADRO 2) (BATISTA, 2018). 
Quadro 2 - Unidades de conservação por categoria de manejo

\begin{tabular}{|c|c|c|c|}
\hline & CATEGORIAS & BRASIL & RN \\
\hline \multirow{8}{*}{ 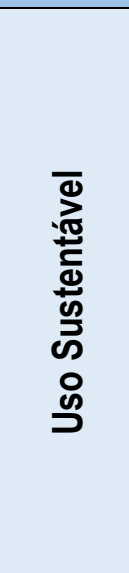 } & Área de Proteção Ambiental & 318 & 4 \\
\hline & Área de Relevante Interesse Ecológico & 49 & 0 \\
\hline & Floresta & 106 & 2 \\
\hline & Reserva Extrativista & 90 & 0 \\
\hline & Reserva de Fauna & 0 & 0 \\
\hline & Reserva de Desenvolvimento Sustentável & 39 & 1 \\
\hline & Reserva Particular do Patrimônio Natural & 859 & 5 \\
\hline & Sub-total & 1461 & 12 \\
\hline \multirow{6}{*}{ 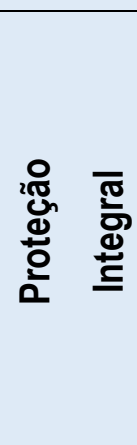 } & Estação Ecológica & 98 & 1 \\
\hline & Reserva Biológica & 62 & 1 \\
\hline & Parque & 417 & 4 \\
\hline & Monumento Natural & 46 & 0 \\
\hline & Refúgio de Vida Silvestre & 60 & 0 \\
\hline & Sub-total & 683 & 6 \\
\hline & TOTAL & 2144 & 18 \\
\hline
\end{tabular}

FONTE: BRASIL (2018c). Organizado por Batista (2018).

Apesar da criação das UC's apresente como um dos objetivo o desenvolvimento de pesquisas científicas e de práticas de educação ambiental, constata-se a falta de estímulo do poder público, conforme pode-se conceber a partir dos valores dos investimentos neste setor, que são praticamente nulos. (FERNANDES, 2011).

\section{Área de Proteção Ambiental de Jenipabu (APAJ)}

As Áreas de Proteção Ambiental (APA's) são UC's com uma das funções proteger / conservar seus ecossistemas. Conforme definido no art. 15 da Lei 9985 , trata-se

[...] uma área em geral extensa, com um certo grau de ocupação humana, dotada de atributos abióticos, bióticos, estéticos ou culturais especialmente importantes para a qualidade de vida e o bem-estar das populações humanas, e tem como objetivos básicos proteger a diversidade biológica, disciplinar o processo de ocupação e assegurar a sustentabilidade do uso dos recursos naturais (BRASIL, 2000). 
Alertou-se para a criação da APAJ mediante a necessidade de se proteger seus ecossistemas, que estavam sendo ameaçados pelo desenvolvimento de práticas turísticas desenfreadas, sobretudo relacionadas a passeios de buggys sobre as dunas de Jenipabu. Assim, a APAJ foi instaurada por meio do decreto estadual $n^{0} 12.620$ de 17 de maio de 1995, objetivando o ordenamento do uso e a proteção dos ecossistemas de praias e dunas, a mata atlântica, os rios e lagoas, o manguezal e as espécies vegetais e animais. A APAJ Apresenta extensão territorial de 1.739 hectares (ha), em um perímetro de 19,6 quilômetros (km), abrangendo as praias de Redinha Nova, Santa Rita e Jenipabu (MAPA 2) (IDEMA, 2009; BATISTA, 2018).

Mapa 2 - Praias situadas na APAJ

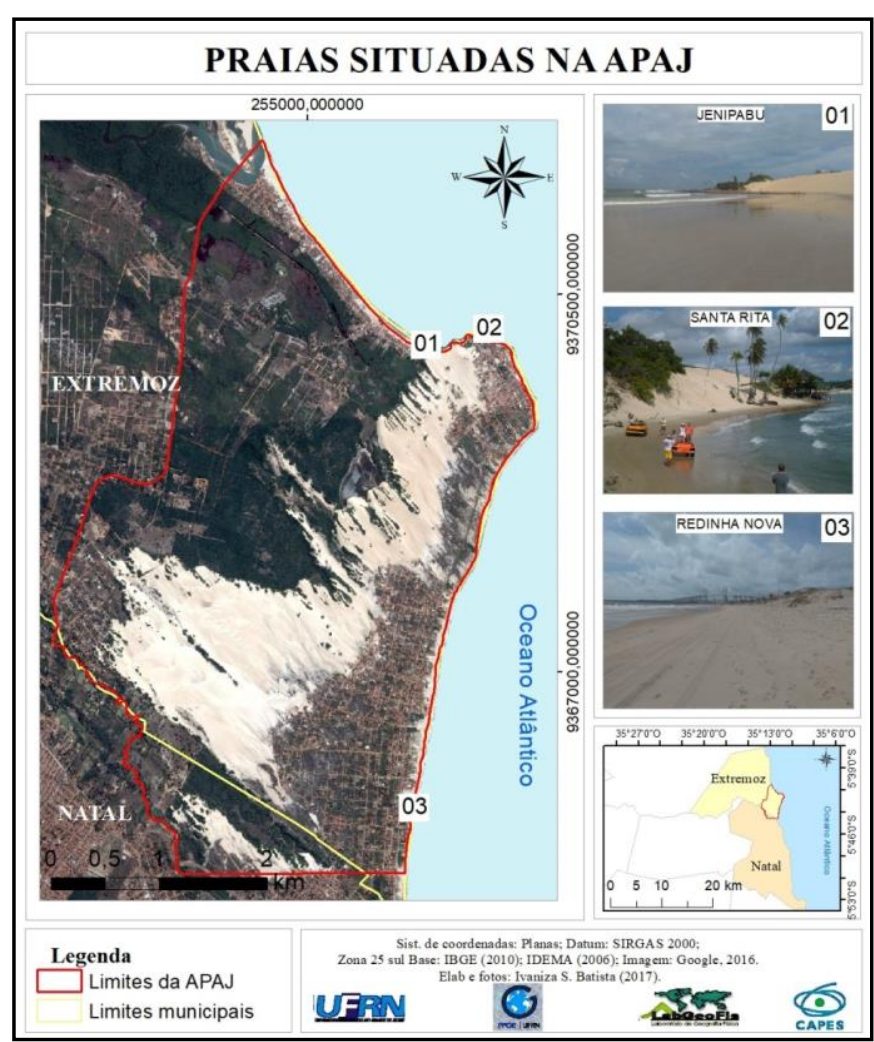

FONTE: IBGE (2010); Google Earth (2016). Adaptado por Batista (2018).

Trata-se de uma área bastante diversa e de grande valor ambiental. Sendo reconhecida por apresentar cenários de beleza singular, cuja diversidade dos sistemas naturais locais vem convengindo na atração histórica de pessoas (moradores, veranistas, turistas e trabalhadores) e investimentos (políticos e econômicos) (BATISTA, 2018). 


\section{Caracterização físico-natural}

A área de estudo apresenta clima As' tropical chuvoso com verão seco (VIANELLO e ALVES, 1991), caracterizado pela conformação de precipitações médias anuais de $1.500 \mathrm{~mm}$ e temperaturas mínimas e máximas oscilando entre $30^{\circ} \mathrm{C} \mathrm{e} 24^{\circ} \mathrm{C}$. As chuvas encontram-se concentras entre fevereiro a agosto (quando os totais mensais, em média, excedem os $100 \mathrm{~mm}$ ) nesse trecho do litoral do RN, sendo os meses considerados de estiagem (total de precipitação, em média, abaixo de $30 \mathrm{~mm}$ ) compreendidos de setembro a janeiro (AGUIAR, 2013; CHAVES, 2000; LIMA, 2011).

$O$ regime de ventos na área tem direção predominante de sudeste, apresentando velocidade média de $4,7 \mathrm{~m} / \mathrm{s}$, com variações vindas de Leste, Sul e NE. Sendo as máximas registradas na ordem de valores entre 8,3 e 10,3 m/s. A umidade relativa do ar na região é de aproximadamente $80 \%$ (média anual), já a insolação total anual incidente se aproxima das 2800 horas, sendo os meses mais ensolarados são de outubro a dezembro (AGUIAR, 2013).

Em relação ao regime de marés, Jenipabu é classificada como área de domínio de mesomaré, com intervalos de aproximadamente 6 horas. São configuradas ondas do tipo mergulhante, com conformação de ondas ascendentes próximo ao "morro de Genipabu", devido a formação de uma baía. Apresentando altura média de $18 \mathrm{~cm}$ e períodos oscilando de $0,45 \mathrm{~min}$ a $1,07 \mathrm{~min}$, com direção preferencial variando entre $310^{\circ}$ a $300^{\circ}$ azimute (Az) (LIMA, 2011).

Em relação a hidrografia, a APAJ, tem como tributários mais importantes os rios Ceará-Mirim e Doce (MAPA 3), tendo sua costa banhada pelo Oceano Atlântico (ao leste). Sendo notória a conformação de lagoas interdunares, originadas em associação com dunas como fonte de alimentação e equilíbrio, assim como, a superficialidade do lençol freático que aflora, diminuindo ou aumentando o volume de suas águas de acordo com a alternância dos períodos de verão e inverno (NUNES, 2006). A Lagoa de Jenipabu é perenizada devido a ressurgência das águas subterrâneas do aquífero Dunas, que preenchem as depressões superficiais aplainadas (IDEMA, 2009).

A da área em estudo está situada na Província Borborema, formada predominantemente por sedimentos da Formação Barreiras, depósitos flúvio-lagunares, litorâneos e dunas inativas (CPRM, 2005), são estruturas geológicas do período Neógeno. Superficialmente destacam-se os sedimentos esbranquiçados que formam as dunas móveis e fixas (BATISTA, 2018). 
Mapa 3 - APAJ: Hidrografia

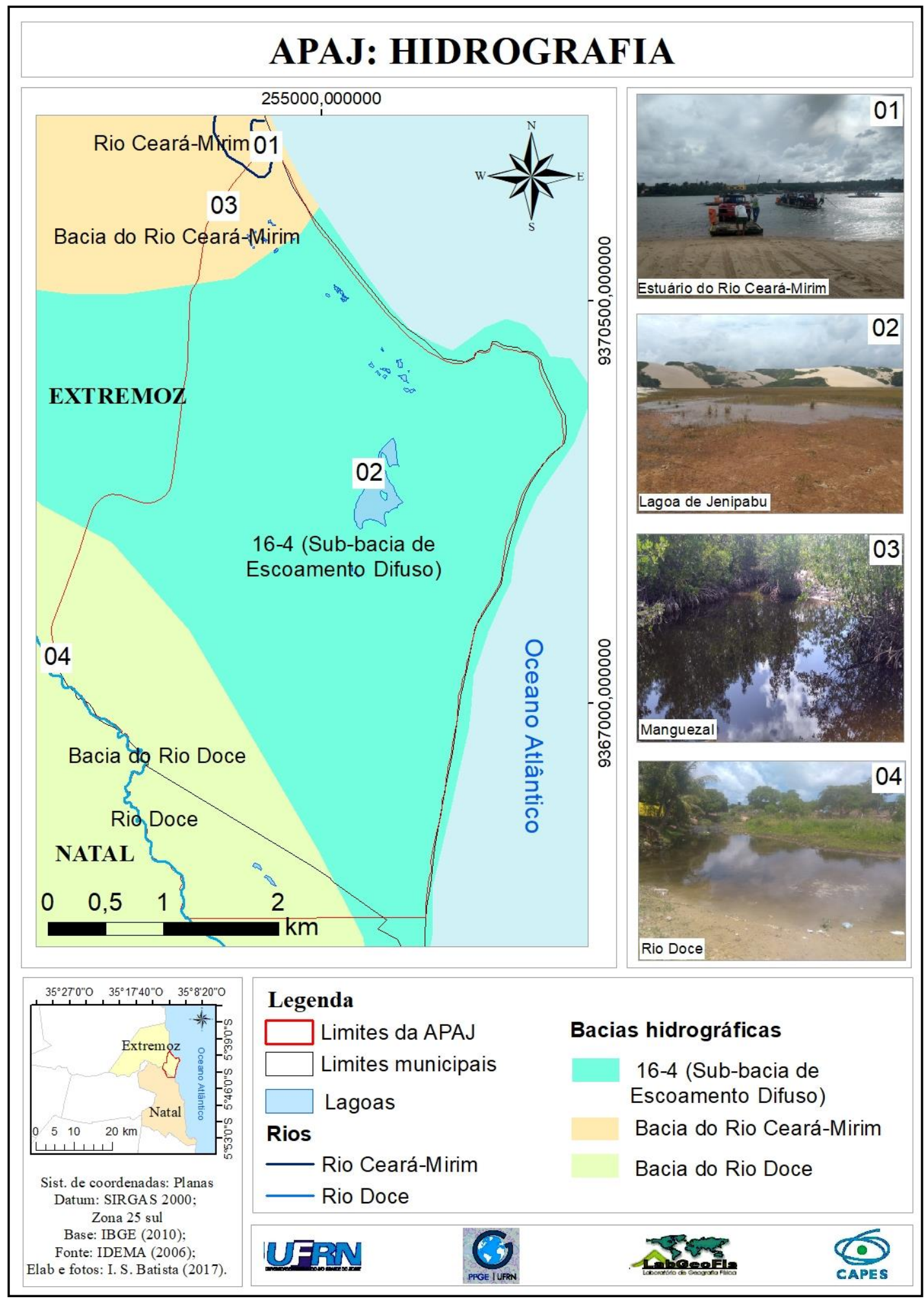

FONTE: IBGE (2010); IDEMA (2006). Adaptado por Batista (2018).

A extensão do campo de dunas móveis no interior da APAJ é bastante expressiva (MAPA 4), apresentando alinhamento paralelo a linha de costa, dispostos entre a planície de deflação e as dunas do Nordeste brasileiro, p. 904-924, Set. 2019, http://uvanet.br/rcgs. ISSN 2316-8056 ๔ 1999, Universidade Estadual Vale do Acaraú. Todos os direitos reservados. 
fixadas por vegetação. Sua fixação é ocorre a partir do processo de pedogênese, associado com o desenvolvimento de vegetação, de modo a impedir a mobilidade dos sedimentos e, consequentemente, fixando-os por meio de seu sistema radicular (IDEMA, 2009; BATISTA, 2018).

Mapa 4- APAJ: Geologia



FONTE: IBGE (2010); CPRM (2006). Adaptado por Batista (2018).

Revista da Casa da Geografia de Sobral, Sobral/CE, v. 21, n. 2, Dossiê: Estudos da Geografia Física do Nordeste brasileiro, p. 904-924, Set. 2019, http://uvanet.br/rcgs. ISSN 2316-8056 @ 1999, Universidade Estadual Vale do Acaraú. Todos os direitos reservados. 
A formação das dunas móveis é resultante dos processos de intemperismo e erosão das rochas e sua posterior deposição no ambiente praial, os ventos transporta-os e formam os campos de o dunas, ao longo da costa e no continente. As dunas fixas na APAJ tem sua localização entre as dunas móveis e o tabuleiro costeiro, lugares que apresentam uma menor intensidade da ação dos ventos, de modo a favorecer o desenvolvimento de uma cobertura vegetal composta por espécies pioneiras herbáceas e arbustivas. Nas porções topograficamente mais elevadas estão distribuídas as coberturas arenosas a areno-siltosas de coloração variada, sobrepostas as rochas sedimentares da Formação Barreiras (IDEMA, 2009).

$\mathrm{Na}$ costa sobressai o domínio das dunas ativas (idades mínimas inferiores a 200 anos), apresentando o formato predominante de barcanas isoladas e cristas barcanóides, associadas as frentes parabólicas transgressivas, com pouca ou nenhuma vegetação. No continente adentro, destaca-se a presença de dunas inativas com formas tênues (com idades muito variáveis, desde 89.000 anos até 0 Holoceno), do tipo parabólicas compostas e simples, somadas as longitudinais (possivelmente resultantes de rastros lineares residuais (trailingridges) de dunas parabólicas) (BARRETO ET AL, 2004).

Tem-se, também, a presença de depósitos fluviais e flúvio-marinhos, em associação com os cursos d' água dos rios Doce e Ceará-Mirim, respectivamente. Assim como, a espacialização de arenitos ferruginosos (ao longo da costa de Santa Rita e Jenipabu), formados a partir do processo de erosão diferencial nas rochas da Formação Barreiras (devido à resistência diferenciada das mesmas aos processos costeiros). Conformando uma plataforma de abrasão com formação de marmitas (BATISTA, 2018).

Em termos geomorfológicos, sobressaem-se as seguintes feições costeiras: a) faixas de praias; b) os campos de dunas móveis e fixas; d) as planícies de deflação. Sendo observadas nas áreas mais altas, no interior do continente, as superfícies de erosão, representadas pelo tabuleiro costeiro. Uma feição com formato plano e ligeiramente inclinado em direção ao litoral, sendo esculpida sobre os sedimentos da Formação Barreiras. Nas áreas compreendidas pelos corredores fluviais, são encontradas as planícies fluvial e flúvio-marinha (MAPA 5), esta última refere-se a em uma área plana formada em associação com processos de acumulação fluvial e marinha (sujeitas inundações periódicas das marés), apresentando vegetação de mangue (IDEMA, 2009 e 2013).

Em relação a composição pedológica, a APAJ apresenta solos associados as coberturas de sedimentos do período Quaternário, representados pelas formações que dão origem aos Neossolos quartzarênicos Órticos, os solos Aluviais, os solos Gleissolos e os Gleissolos Tiomórficos. Somados aos solos que mantém relação com a Formação Barreiras, tais como as planícies sedimentares costeiras (tabuleiros) que dão originam os Latossolos (NUNES, 2000). 
Mapa 5 - APAJ: Geomorfologia

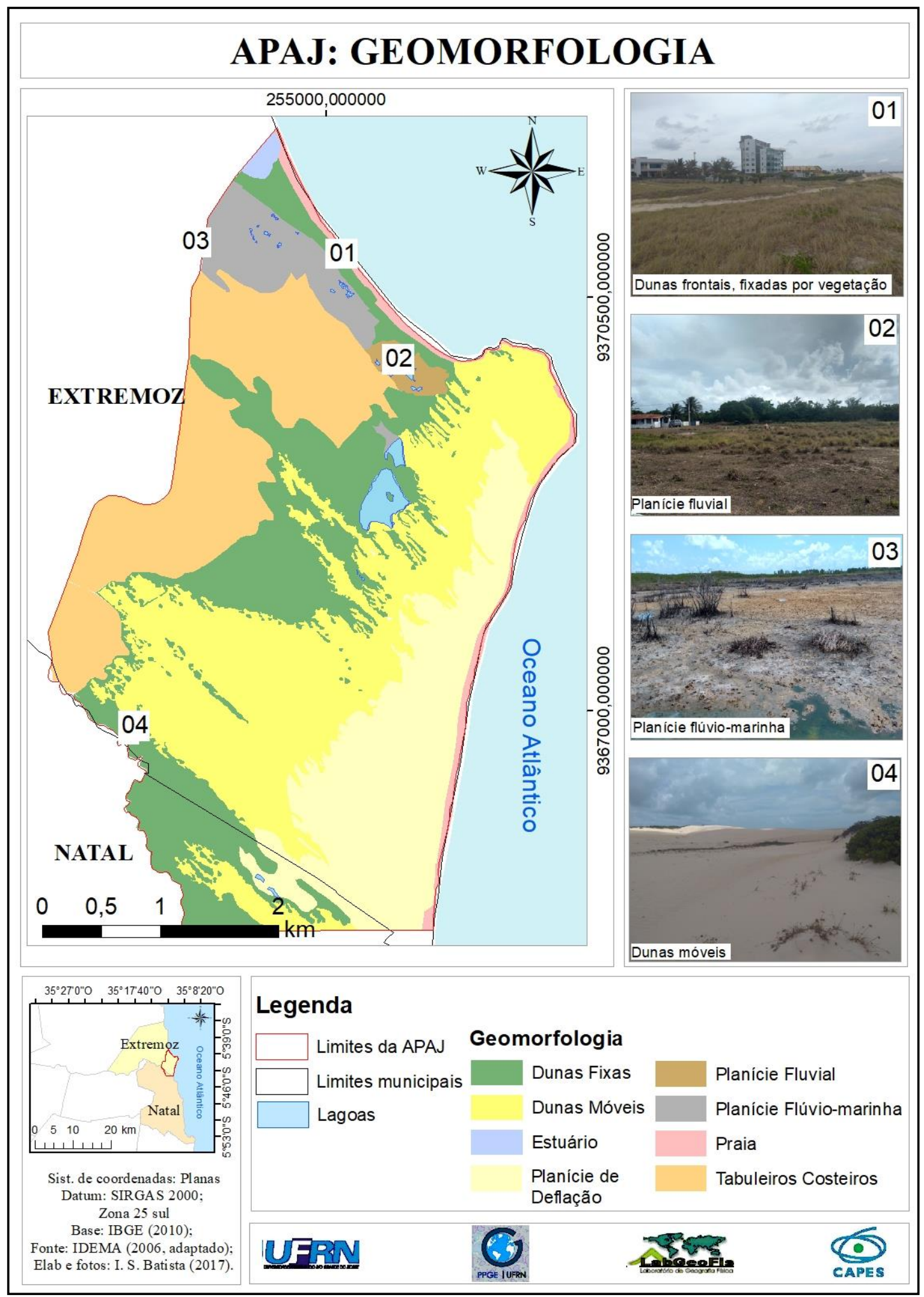

FONTE: IBGE (2010); IDEMA (2006). Adaptado por Batista (2018).

Os Neossolos Quartzarênicos Órticos apresentam composição essencialmente quartzosa, textura arenosa, baixa fertilidade natural, elevada permeabilidade e porosidade, ausência de minerais do Nordeste brasileiro, p. 904-924, Set. 2019, http://uvanet.br/rcgs. ISSN 2316-8056 ๑ 1999, Universidade Estadual Vale do Acaraú. Todos os direitos reservados. 
primários alteráveis e grande profundidade (EMBRAPA, 2006; NUNES, 2006). Sua distribuição ocorre ao longo de toda a faixa litorânea da área em estudo, formando as coberturas arenosas de praias e dunas (MAPA 6).

Mapa 6 - APAJ: Pedologia

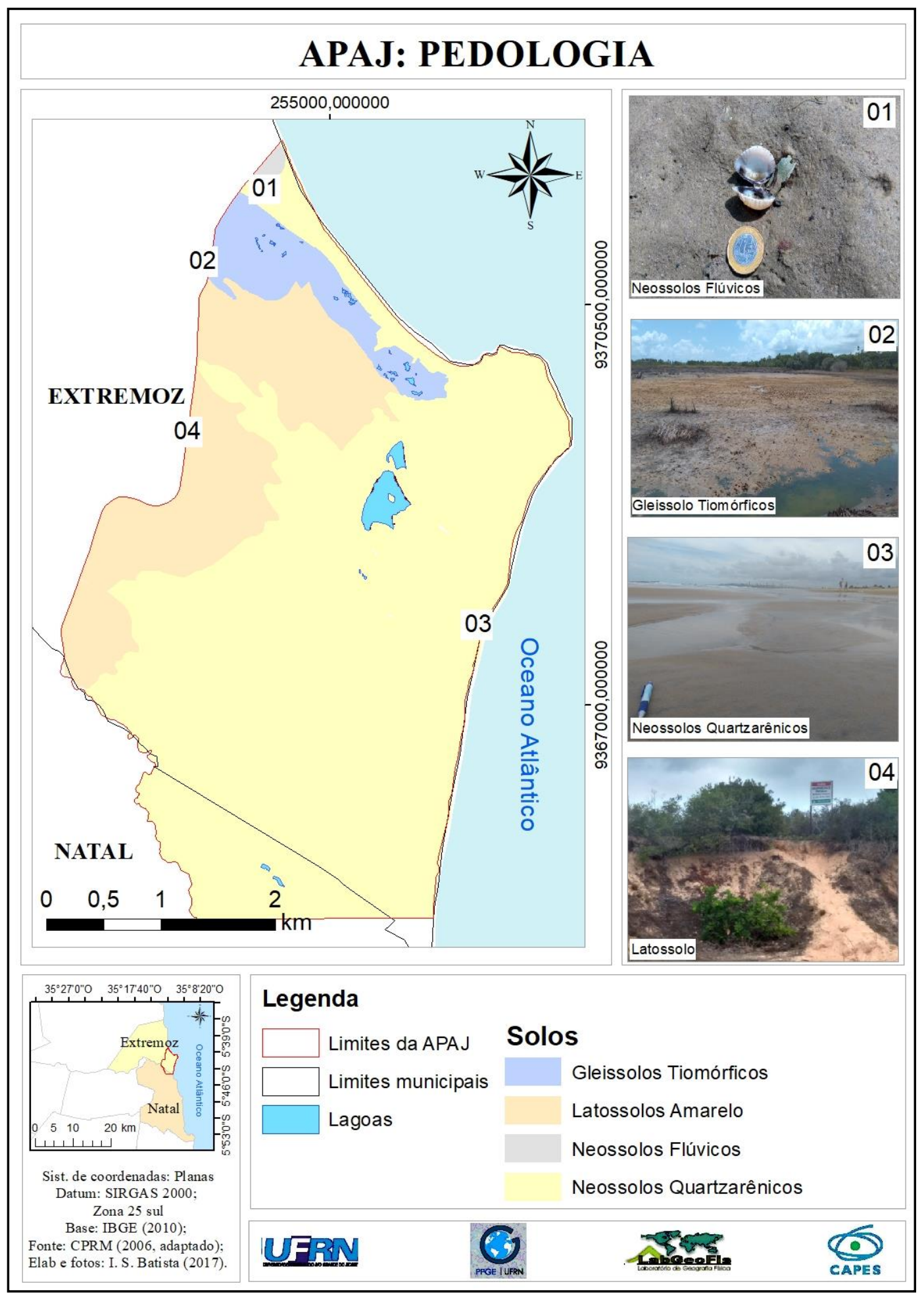

FONTE: IBGE (2010); IDEMA (2006). Adaptado por Batista (2018).

Revista da Casa da Geografia de Sobral, Sobral/CE, v. 21, n. 2, Dossiê: Estudos da Geografia Física do Nordeste brasileiro, p. 904-924, Set. 2019, http://uvanet.br/rcgs. ISSN 2316-8056 ๔ 1999, Universidade Estadual Vale do Acaraú. Todos os direitos reservados. 
Os Neossolos situados ao longo dos vales dos rios apresentam pouco desenvolvimento, e elevada fertilidade natural. Os Latossolos, por sua vez, são caracterizados pelo avançado estágio de intemperização, pelo seu bom desenvolvimento e drenagem, por sua acidez e baixo teor de matéria orgânica. São solos planos e suavemente inclinados encontrados com proximidade com o litoral, limitando-se com as dunas. Os Gleissolos são solos com coloração escura (cinza), apresenta grande quantidade de matéria orgânica, elevado nível de acidez e bastante mal drenados. Já os Gleissolos Tiomórficos, são caracterizados pela má drenagem, compostos de enxofre, elevada salinidade e influência da maré (EMBRAPA, 2006; NUNES, 2006).

Por fim, a cobertura vegetal, na APAJ é representada pela distribuição espacial de espécies vegetais associadas aos campos de praias e dunas, tabuleiros costeiros e planícies fluvial e flúviomarinha. Sobre as feições dunares, têm-se como principais espécies a "salsa" Ipomoea pes-caprae Roem. \& Schult (FIGURA 1), o "pinheirinho da praia" Remirea maritima Aublet., a "crista de galo" Heliotropium sp e a "beldroega" Sesuvium portulacastrum L., além de diversificados tipos de gramíneas (poaceae) e ciperáceas. Recobrindo as dunas fixas encontra-se a vegetação pioneira marinha arbustiva, destacando-se nas dunas de Jenipabu, a espécie Anacardium occidentale L.(cajueiro), apresentando extensas raízes assegurando a sua fixação à mobilidade do solo (IDEMA, 2009).

Figura 1 - "Salsa" Ipomoea pes-caprae Roem. \& Schult sobre dunas

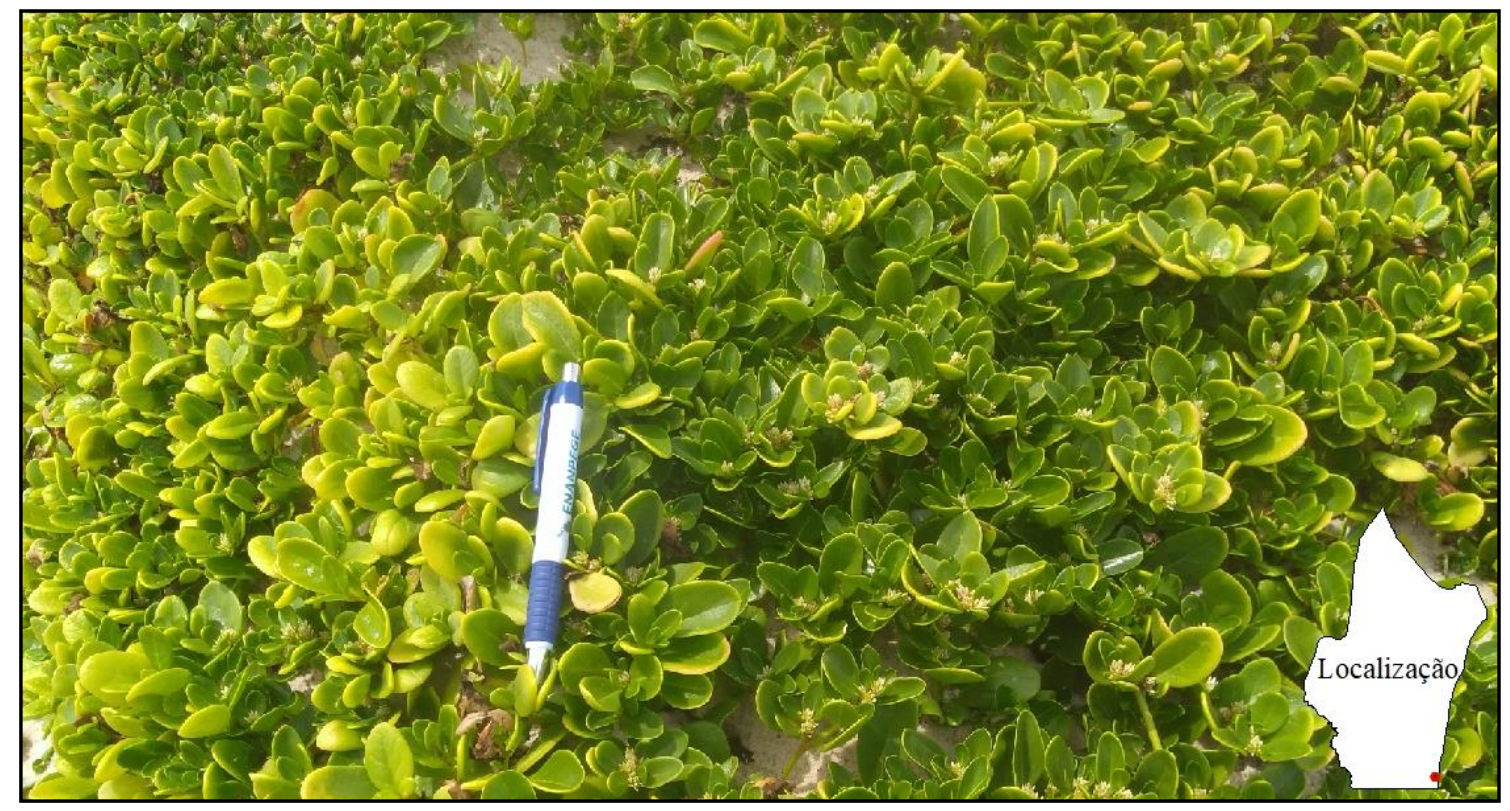

FOTO: Batista (2018).

Na Lagoa de Jenipabu sobressai-se a conformação de macrófitas aquáticas, exemplificadas pela Nymphoides indica (L.) O. Kuntze (Menyanthaceae), Juncussp (Juncaceae), Eichornia crassipes. Em seu do Nordeste brasileiro, p. 904-924, Set. 2019, http://uvanet.br/rcgs. ISSN 2316-8056 @ 1999, Universidade Estadual Vale do Acaraú. Todos os direitos reservados. 
entorno, encontra-se uma vegetação arbustiva-arbórea de espécies como "aroeira da praia" Schinus terenbitifolius L., "murici" Byrsonima sp, "ipê roxo" TabebuiaavellanedaeLor. Ex.Griseb.e algumas outras espécies como gramíneas (poaceae) e ciperáceas que se desenvolvem em áreas brejosas da APAJ (FIGURA 2) (IDEMA, 2009).

Figura 2 - Vegetação na lagoa de Jenipabu e em seu entorno

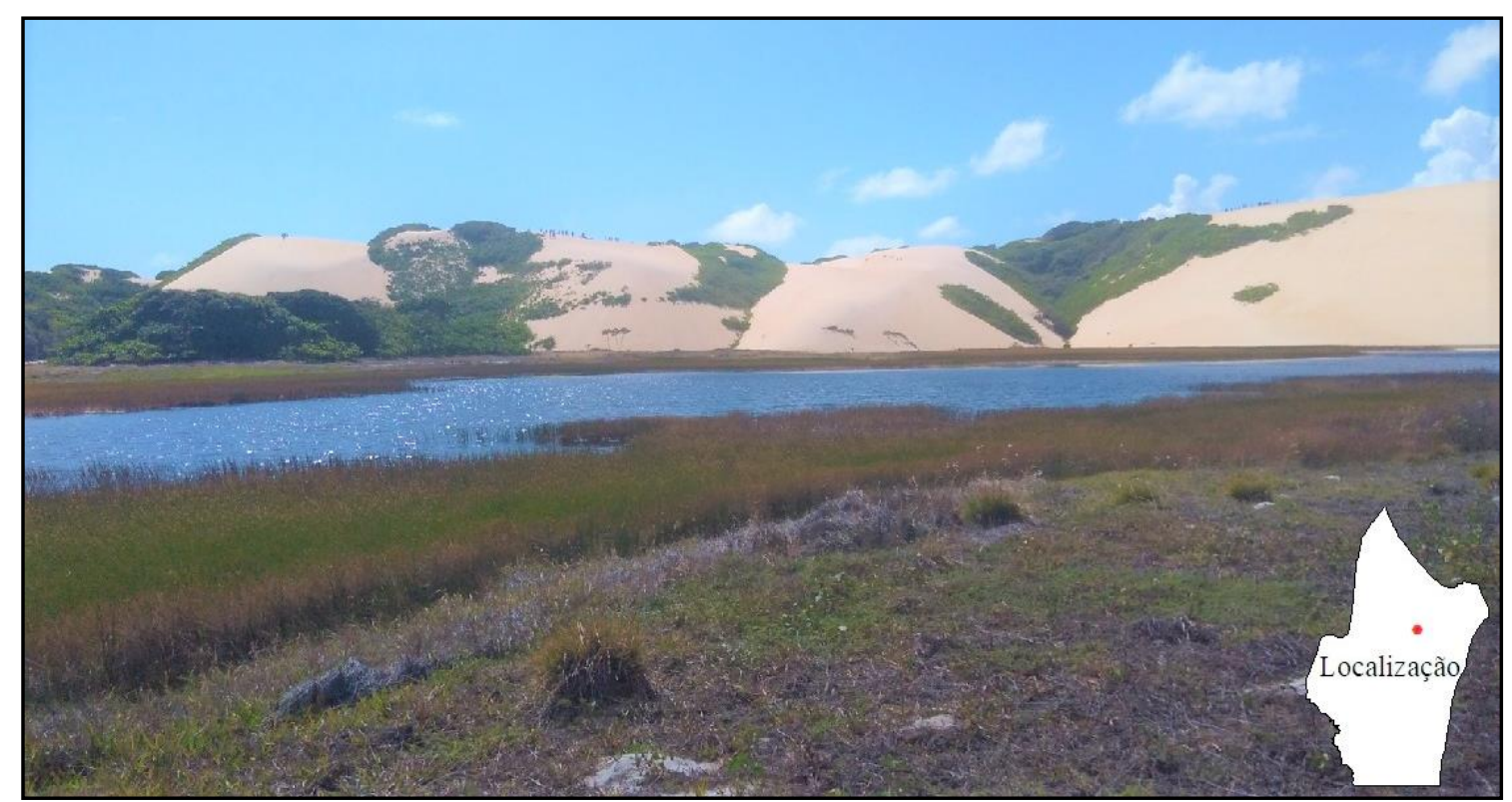

FOTO: Batista (2018).

Em associação com os tabuleiros, ocorre a distribuição de uma vegetação predominantemente arbustiva esparsa com algumas árvores intercaladas, na parte do relevo mais baixo. Sendo as principais representantes a Krameria tomentosa (Krameriaceae), Miconiasp (Melastomataceae), Ceres jamacaru (Cactaceae), Solanumpaniculatum (Solanaceae). No sub-bosque tem-se o domínio de ciperáceas e gramíneas (poaeceae), leguminosas, exemplificadas pela Curatella americanaL. (Dilleniaceae) (IDEMA, 2009).

No que se concerne à vegetação arbórea, sobressai-se as espécies da família Myrtaceae (Myrcia, Eugenia, Psidium), Caesalpinia echinata (pau brasil), Tapirira guianensis, Andira nitida,Byrsonima gardneriana, Schinus terenbitifolius. Além da presença de orquídeas, bromélias, aráceas, cactáceas e a floresta atlântica. Sendo esta última, representada pelas espécies: Arrabideasp, Jacquemontia sp, Merremia dissecta, Evolvulus sp, Tetracerabreyniana (IDEMA, 2009).

Por fim, nas áreas com influência flúvio-marinha, tem-se a presença da vegetação de manguezal, cujas representantes são a Rhizophora mangle (mangue sapateiro), Avicenia schaueriana (mangue branco ou mangue-canoé), Laguncularia recemosa (mangue manso), Acrostrichum aureum (avenção ou samambaia-do-mangue) e Conocarpu serecta (mangue-ratinho ou mangue-botão) (NUNES, 2006). do Nordeste brasileiro, p. 904-924, Set. 2019, http://uvanet.br/rcgs. ISSN 2316-8056 ๔ 1999, Universidade Estadual Vale do Acaraú. Todos os direitos reservados. 
Trata-se de uma formação vegetal típica de regiões alagadiças, cuja característica marcante é raiz externa aérea, uma adaptação estrutural em busca da sobrevivência (para capturar oxigênio na superfície). 0 ecossistema de manguezal é hidromórfico (mal drenado, com estagnação de água), apresenta reduzida oxigenação e elevada concentração de sal (BATISTA, 2018).

Em linhas gerais, distingui-se a conformação de três grandes grupos vegetais: 1 - pioneiras herbáceas e arbustivas com influência marinha; 2 - savana arborizada e a Floresta estacional ou Semidecidual; 3 - formações pioneiras arbóreas e herbáceas com influência fluvial e flúvio-marinha (MAPA 7).

MAPA 7 - Cobertura do solo - APA Jenipabu

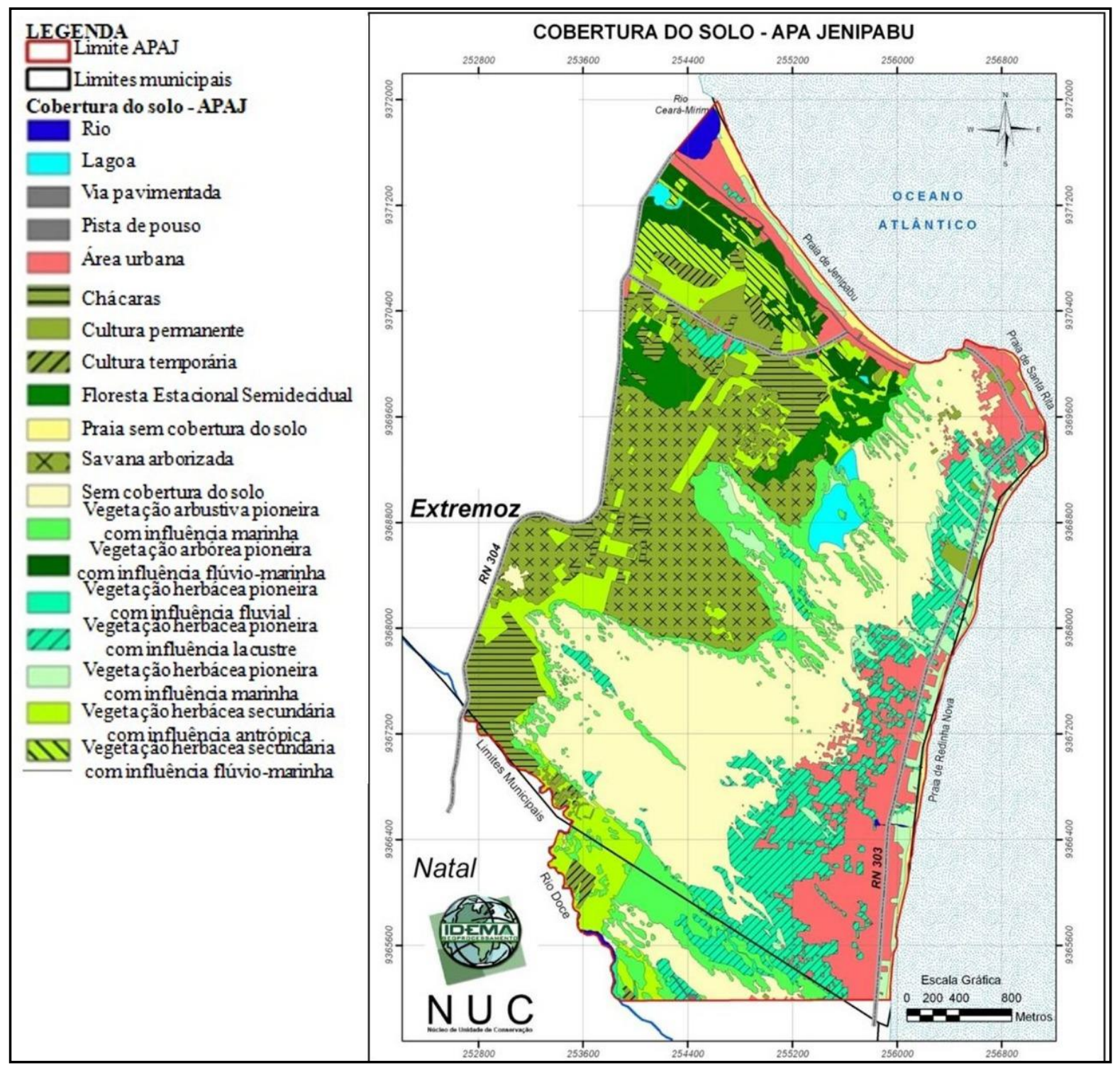

FONTE: IDEMA (2006). Adaptado por Adriano Wagner (2018). 
O primeiro grupo vegetal é representado por espécies halo-psamófilas (com função fixadora), situadas sobre praias e dunas. São ralas nas adjacências de deflação e nos interiores, todavia, tornamse densas nas faixas de sotavento (IDEMA, 2009). O segundo grupo, recobrem os tabuleiros costeiros e são caracterizados por sua fisionomia variada (densas, esparsas, formação de moitas abertas e fechadas). Por fim, o terceiro grupo é típico de áreas com influência flúvio-marinha, conformando vegetação tropical típica paludosa de mangue (IDEMA, 2009).

Dessa forma, a área de estudo caracteriza-se pela conformação de sistemas ambientais de bastante dinâmicos e estão em permanente processo de (re) modelagem da sua composição paisagística. Por permitir o desfrute e uso direto dos seus recursos e potencialidades, maior é a probabilidade de degradação dos seus ecossistemas, em consonância com as práticas socioespaciais desenvolvidas, localmente. Verifica-se, localmente, o desenvolvimento de atividades diversas, sobretudo, associadas a economia turística (BATISTA, 2018).

Dentre os atrativos turísticos observados na área em estudo, destacam-se o Aquário de Natal, os passeios de dromedários, jegues e buggys nas dunas, vendas de produtos artesanais, a travessia de balsa e descidas sobre as dunas, recreação e lazer em lagoas e praias, além de serviços de bar e restaurante (AGUIAR, 2013; BATISTA, 2014 e 2018). A maioria dessas atividades desencadeiam uma série de conflitos, problemas e impactos ambientais (IDEMA, 2009), cabe aos gestores da APAJ e a sociedade como um todo buscar a conciliação entre os usos e ocupação do solo e a conservação do mosaico de ecossistemas locais (BATISTA, 2018).

\section{CONSIDERAÇÕES FINAIS}

A constituição de UC's é de fundamental importância para a preservação e/ou conservação de áreas que apresentam relevância biótica e / ou abiótica, de modo, a assegurar legalmente o uso direto ou indireto dos recursos naturais disponíveis. APAJ é reúne um mosaico de distintos ambientes de sedimentação marinha, eólica, fluvial, flúvio-marinha e terrígena, os quais compõem paisagens exuberantes, amplamente explorados pelo turismo.

A consorciação de diferentes atividades, ligadas principalmente a economia turística, somadas as demais formas de uso e ocupação do solo dentro da UC, têm contribuído significativamente para a conformação de mudanças na paisagem da APAJ, assim como o comprometimento dos ecossistemas que a compõem, em conformidade com o grande potencial modificador das interferências antrópicas.

Neste sentido, reitera-se a importância desempenhada de ações voltadas para 0 monitoramentos das formas de uso e ocupação do solo; a promoção de ações sustentáveis direcionadas 
para a conscientização ambiental (através de projetos de educação ambiental, por exemplo); o incentivar a realização de pesquisas e o desenvolvimento de atividades coadunáveis com a capacidade de suporte local. Portanto, salienta-se a importância desempenhada por uma gestão participativa (composta por gestores e comunidades locais), visando o equacionamento de conflitos e a proteção/conservação dos ecossistemas e biodiversidade local.

\section{REFERÊNCIAS}

AGUIAR, L. de S. Dinâmica ambiental da planície de deflação do litoral de Extremoz/RN. 2013. 147f. Dissertação (Mestrado em Geografia) - Universidade Federal do Rio Grande do Norte, Natal, 2013.

BARRETO, A. M. F.; SUGUIO, K.; BEZERRA, F. H. R.; TATUMI, S. H.; YEE, M.; GIANNINI, P. C. F. Geologia e geomorfologia do quaternário costeiro do estado do Rio Grande do Norte . Geologia USP. Série Científica, São Paulo, v. 4, n. 2, p. 1-12, oct. 2004. Disponível em: <http://www.revistas.usp.br/guspsc/article/view/27395/29167>. Acesso em: 27, maio 2018.

BATISTA, I. S. Ocupação do solo e mudanças na paisagem na área de proteção ambiental de Jenipabu (APAJ). Dissertação (mestrado) - Universidade Federal do Rio Grande do Norte. Centro de Ciência Humanas, Letras e Artes. Programa de Pós-Graduação e Pesquisa em Geografia. Natal, RN, 2018. - 2018. 134 f.

. Evolução do uso e cobertura do solo na zona costeira de Extremoz entre 1970 e 2006. Monografia (Graduação em Geografia) - Universidade Federal do Rio Grande do Norte, Natal, 2014.

BRASIL. Brasilia: Presidência da República - Casa civil. Constituição da República Federativa do Brasil De 1988. Disponivel em: <http://www.planalto.gov.br/ccivil_03/constituicao/constituicao.htm>. Acesso em 23, Jun 2018. 1988.

. Sistema Nacional de Unidades de Conservação - SNUC. Lei no 9.985 de 18 Julho de 2000. Regulamenta o art. 225, § 1o, incisos I, II, III e VII da Constituição Federal, institui o Sistema Nacional de Unidades de Conservação da Natureza e dá outras providências. 2000.

Ministério do Meio Ambiente. Sistema Nacional de Unidades Conservação. Disponível em: < http://www.mma.gov.br/areas-protegidas/sistema-nacional-de-ucs-snuc>. Acesso em: 17, Fev 2018. 2018b. . Ministério do Meio Ambiente. Cadastro Nacional de Unidades de Conservação. Disponível em: $<$ <ttp://www.mma.gov.br/areas-protegidas/cadastro-nacional-de-ucs>. Acesso em: 17, Fev 2018. 2018c.

CHAVES, M. dos S. Sedimentologia, morfologia praial e vulnerabilidade costeira entre as praias da Redinha e Jenipabu, Natal/RN. Dissertação (Mestrado). Recife/PE: UFPE, Geociências, 2000. do Nordeste brasileiro, p. 904-924, Set. 2019, http://uvanet.br/rcgs. ISSN 2316-8056 @ 1999, Universidade Estadual Vale do Acaraú. Todos os direitos reservados. 
CPRM - SERVIÇO GEOLÓGICO DO BRASIL. Projeto cadastro de fontes de abastecimento por água subterrânea. Diagnóstico do município de Extremoz, estado do Rio Grande do Norte. MASCARENHAS, J. de C.; BELTRÃO, B. A.; SOUZA JUNIOR, L. C. de; PIRES, S. de T. M.; ROCHA, D. E. G. A. da; CARVALHO, V. G. D. de. (Org). Recife: CPRM/PRODEEM, 2005.

. Ministério de Minas e Energia. Geologia e recursos minerais do Estado do Rio Grande do Norte. Programa Geologia do Brasil. Mapeamento Geológico. Integrações Geológicas Regionais. ANGELIN, L. A. de A.; NESI, J. de R.; TORRES, H. H. F.; MEDEIROS, V. C. de; SANTOS, C. A. dos; VEIGA JUNIOR, J. P.; MENDES, V. A.. (Org). Recife: CPRM, 2006.

EMBRAPA - Empresa Brasileira de Pesquisa Agropecuária. Sistema brasileiro de classificação de solos. 2. ed. - Rio de Janeiro : EMBRAPA-SPI, 2006. $306 \mathrm{p}$.

FARIA, H. H. de; PIRES, A. S. Atualidades na gestão de unidades de conservação. In: ORTH, D.; DEBETIR, E. (org). Unidades de conservação: gestão e conflitos. Florianópolis: Insular, 2007. 168 p. (Coleção Grupo GE)

FERNANDES, M. C. Empreendedorismo ambiental e "preservacionismo" compensatório: o turismo e as unidades de conservação Parque Estadual das Dunas e Área de Proteção Ambiental Jenipabu - RN. Tese (Doutorado em Ciências Sociais) - Universidade Federal do Rio Grande do Norte. Centro de Ciências Humanas, Letras e Artes. Programa de PósGraduação em Ciências Sociais, Natal, 2011. 245 p.

GOVERNO DO RIO GRANDE DO NORTE. Gabinete Civil. Decreto nº 12.620 de 17 de Maio de 1995. Cria a Área de Proteção Ambiental (APA) Genipabu, nos Municípios de Extremoz e Natal e dá outras providências. 1995. IDEMA - Instituto de Desenvolvimento Sustentável e Meio Ambiente do Rio Grande do Norte. Plano de Manejo da Área de Proteção Ambiental - APA Jenipabu. Relatório de Consolidação. Natal, Maio de 2009. 174 p

Perfil do seu município. Extremoz, RN. 2013.

LIMA, J. S. D. de. Análise e monitoramento geoambiental na Praia de Genipabu, Extremoz/RN. Dissertação (Mestrado) - Universidade Federal do Rio Grande do Norte. Centro de Ciências Humanas, Letras e Artes. Programa de Pós-Graduação em Geografia. Natal, RN: 2011. 114 f.

MEDEIROS, R. A política de criação de áreas protegidas no Brasil: evolução, contradições e conflitos. Anais do IV Congresso Brasileiro de Unidades de Conservação, vol 1. Curitiba: Fundação O Boticário de Proteção à Natureza \& Rede Pró Unidades de Conservação, 2004.

MEDEIROS, J. de D. Criação de Unidades de Conservação no Brasil. In: ORTH, D.; DEBETIR, E. (org). Unidades de conservação: gestão e conflitos. Florianópolis: Insular, 2007. 168 p. (Coleção GrupoGE)

NUNES, E. 0 meio ambiente da grande Natal. Natal: Imagem, 2000. 118 p. do Nordeste brasileiro, p. 904-924, Set. 2019, http://uvanet.br/rcgs. ISSN 2316-8056 ○ 1999, Universidade Estadual Vale do Acaraú. Todos os direitos reservados. 
Geografia física do Rio Grande do Norte. 1. ed. Natal: Imagem Gráfica, 2006. 114 p.

VIANELLO, R. L.; ALVES, A. R. Meteorologia básica e aplicações. Viçosa, MG: Imprensa Universitaria, UFV, 1991. 449 p. 